\title{
Fractional Iron Absorption
}

National Cancer Institute

\section{Source}

National Cancer Institute. Fractional Iron Absorption. NCI Thesaurus. Code C161349.

A relative measurement (ratio or percentage) of the iron absorbed into tissue or cells to the total available iron. 